\title{
Relationship Between Loneliness and Mental Health Among First- Year Undergraduate Students: Mediating Role of Timeline Browsing and Chatting on Facebook
}

\author{
Oli Ahmed \\ Correspondence: Lecturer, Department of Psychology, University of Chittagong, Bangladesh. \\ E-mail:oliahmed_polash131@cu.ac.bd
}

Received: September 17, 2018

Accepted:October 22, $2018 \quad$ Online Published: October 29, 2018

doi:10.11114/ijce.v1i2.3625

URL: https://doi.org/10.11114/ijce.v1i2.3625

\begin{abstract}
Better academic performance is associated with adjustment in the educational institution. Newly enrolled students at undergraduate programs face some adjustment related problems (i. e. - loneliness etc.) in the new environment. The present study was aimed to explore the mediating role of Facebook timeline browsing and chatting with friends on Facebook in the relationship between loneliness and mental health among first-year undergraduate students. The study sample comprised of 180 first-year students who were selected purposively from the University of Chittagong. Results suggested significant gender differences in feelings of loneliness, chatting on Facebook, Facebook timeline browsing. Results explored the mediating role of timeline browsing in the relationship between loneliness and mental health, and this relation also moderated by gender. Loneliness, timeline browsing, and gender explained $50 \%$ variance of the mental health.
\end{abstract}

Keywords: loneliness, chatting, Facebook timeline browsing, mental health, gender, first year students

\section{Introduction}

Education is one of the basic rights of human being. A properly educated country can move forward at the top of its development. So, all countries have emphasized the quality education for many years. Quality of education can be defined as 'inputs (number of teaching staffs, their training etc.), processes (amount of instructional time, the extent of active learning etc.), outputs (academic achievement), and outcomes (performance in subsequent sectors)' (Ahmed, Uddin, \& Khanam, 2016). Ensuring quality education at all level is one of the prime visions of the present government of Bangladesh. There are three layers in the existing education system in Bangladesh. Undergraduate and graduate levels of education are at the tertiary level (Ministry of Education, 2012). The age range of students at the entry level in the undergraduate program is 18-19 years. This age range corresponds with one of the major transition periods of life (transition from adolescent to adulthood). From author observation, in Bangladesh, most of the first year undergraduate students are stayed outside of their family for the first time. They have to adjust to a new environment and a new culture, interact with new people. First-year students' adjustments (social, psychological, and academic) are topics of interest by educators (Robbins et al., 2014). There is a strong relationship between adjustment at the new academic institution and academic achievement (Wintre \& Bowers, 2007). It would be difficult for a person to adjust in a new environment and continue his daily activities normally. Having intimate and meaningful social relations with others is important at early adulthood period. If the development of such relations is impeded, people are likely to have the feeling of loneliness. An individual's poor relationships with others contribute to the high level of loneliness (Vanhalst, Luyckx, \& Goossens, 2014). Loneliness is the reality for newcomers (Russell, Peplau, \& Cutrona, 1980).

Loneliness is the subjective feeling of inadequate warmth and intimated social relationship with other people. It is a state of emotional distress from the discrepancy between desired and actual social relationship (Peplau \& Perlman, 1982). Loneliness, as a multidimensional concept (Weiss, 1973), has two dimensions - social and emotional. Earlier is caused by inadequate social relationships that lead to the feelings of exclusion from the group, boredom, etc., and later is caused by absence of intimate emotional attachments with others that leads to distress (Gierveld \& Tilburg, 2006; Weiss, 1973). Loneliness is a widespread problem regardless of age, race, gender, and culture (Rokach \& Neto, 2000). Most of the people have some experience of such isolation in any stages of lives (Rokach \& Brock, 1997). There is a vicious circle of loneliness where people having the feeling of loneliness, suffer from disturbance in daily activities 
(Stensland, Thoresen, Wentzel-Larsen, Zwart, \& Dyb, 2014; Woodhouse, Dykas, \& Cassidy, 2012). Loneliness is associated with mental health (Richardson, Elliott, \& Roberts, 2017).

Mental health is an indispensable part of our health. The World Health Organization (2004) defined mental health as a matter of well-being by which people understand their own capacity, can meet challenges of everyday life, can work adequately and contribute effectively to their society. Studies showed that loneliness associated with self-esteem (Brage, Meredith, \& Woodward, 1993; Civitci \& Civitci, 2009), life satisfaction (Civitci \& Civitci, 2009), anger, anxiety (Johnson, LaVoie, Spenceri, \& Mahoney-Wernli, 2001; Richardson et al., 2017), depression (Cacioppo et al., 2006; Lau, Chan, \& Lau, 1999; Richardson et al., 2017), suicidal ideation (Roberts, Roberts, \& Chen, 1998). Santini, Koyanagi, Tyrovolas, Mason, and Haro (2015), from their systematic review, reported that mental health was negatively influenced by poor social relationships. Meltzer et al. (2013) found that loneliness was strongly related to depression, obsessive-compulsive disorder, and phobias.

The present age is the era of information technology. People have connected with others person virtually also. There are several social networking sites (SNSs) for virtual social connection (i. e. Facebook, Twitter, etc.). Studies suggested an association between loneliness and SNSs use. People who have more feelings of loneliness use the internet more for emotional support (Morahan-Martin \& Schumacher, 2003). Bozoglan, Deirer, and Sahin (2013) reported the loneliness as a significant predictor of internet addiction. Perceived loneliness has a negative association with the intensity of Facebook use (Shettar, Karkal, Kakunje, Meddonsa, \& Chandran, 2017). Socially anxious people are using Facebook more to reduce their loneliness (Sheldon, 2008). In a study, author found that SNSs use negatively correlated with the mental health of students, from different years, from Chittagong University (Sultana, 2018). A study suggested that major depressive disorders, bipolar-mania, dysthymia, narcissism, etc. were predicted by Facebook use (Rosen, Whaling, Rab, Carrier, \& Cheever, 2013). Individuals, who browsed Facebook timeline only not interacting with others, reported worse feelings afterward (Ginsber \& Burke, 2017). Ginsber and Burke (2017) shared results of two studies in the article, titled 'Hard Questions: Is Spending Time on Social Media Bad for Us?,' in the news blog of Facebook. In one study, students were randomly assigned to read the timeline only or post or chat with friends on their Facebook timeline. Results revealed that students, who were read timeline only, were in a worse mood than students who posted or chatted on their Facebook timeline. Another study revealed that people, who clicked on Facebook links or liked posts more than twice that average people, reported worse mental health.

In Bangladesh, Facebook is the most popular social networking sites. Statistics suggested that $91.93 \%$ of SNS users are using Facebook in Bangladesh (State Counter, 2018). Emerging adults and young adults are a large portion of the active users of Facebook in Bangladesh. University first-year undergraduate students are emerging adults. For better adjustment in the new environment, and better academic performance, it would be necessary to explore the relationship among loneliness, mental health, and associated factors those contribute to the relationship between loneliness and mental health. The present study was aimed to explore the mediating role of timeline browsing, and chatting on Facebook in the relationship between loneliness and mental health among university first-year undergraduate students. From the above discussion about loneliness, mental health, and Facebook timeline browsing and chatting on Facebook, a model hypothesized and tested. The proposed model is presented in Figure 1. Along with this objective, the present study was intended to explore mean differences in loneliness, Facebook timeline browsing, chatting on Facebook, and mental health by respondents' gender and residence place.

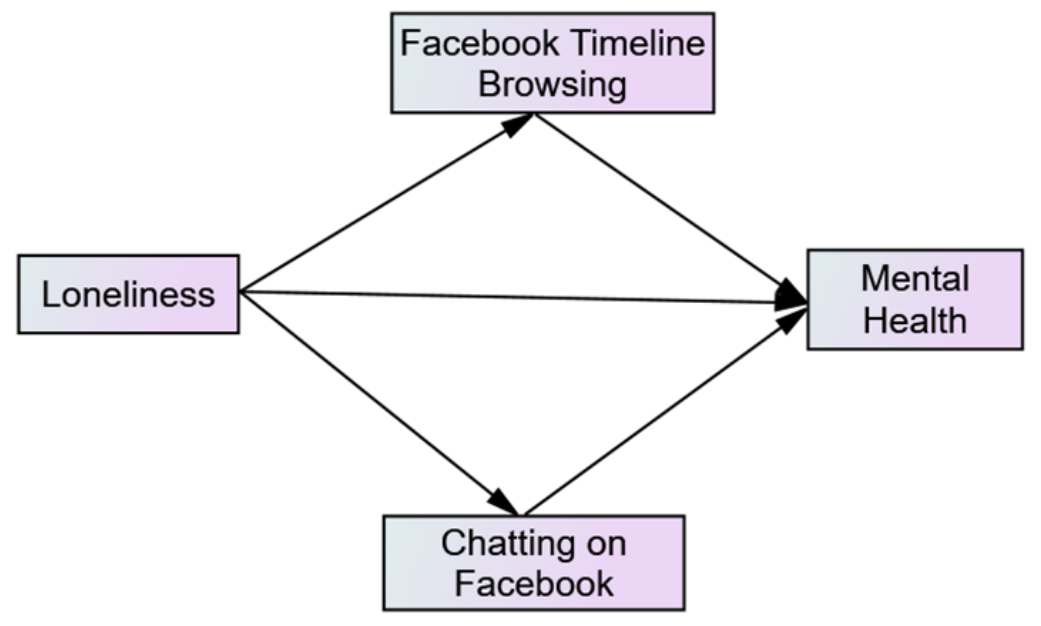

Figure 1. Hypothesized model of the present study 


\section{Method}

\subsection{Participants}

First-year university students at undergraduate level were the population of the present study. Among universities, the University of Chittagong was selected on the basis of convenience. Every year, around 4700 students get enrollment in this university. The study sample comprised of 180 students who selected through the convenience sampling. Their age mean was 18.97 years $(95 \%$ CI $[18.80,19.14])$ with standard deviation of 1.17 years. The sample distribution in respondents' residence type (urban and suburban) and family type by their gender is presented in Table 1 .

Table 1. Respondents' distribution in academic year, residence type, and family type by their gender

\begin{tabular}{cccccc}
\hline \multirow{2}{*}{ Faculty } & \multicolumn{2}{c}{ Residence } & & \multicolumn{2}{c}{ Family Type } \\
\cline { 2 - 3 } \cline { 5 - 6 } & Suburban & Urban & & Single & Extended \\
\hline Male & $26(14.44 \%)$ & $46(25.56 \%)$ & & $60(33.33 \%)$ & $12(6.67 \%)$ \\
Female & $22(12.22 \%)$ & $86(47.78 \%)$ & & $96(53.33 \%)$ & $12(6.67 \%)$ \\
Total & $48(26.67 \%)$ & $132(73.33 \%)$ & & $156(86.67 \%)$ & $24(13.33 \%)$ \\
\hline
\end{tabular}

\subsection{Measures}

In the present study, the Bangla (Ahmed \& Hossain, 2018) UCLA Loneliness Scale - version 3 (Russel, 1996), and the the Bangla version (Ilyas \& Ayesha, 2001) of General Health Questionnaire - 12 (GHQ-12: Goldberg, 1978) were used to collect information about respondents' feelings of loneliness, and mental health. Along with these measures, respondents were asked two questions about their per day average time spending on timeline browsing and chatting on Facebook.

The UCLA Loneliness Scale - version 3: The original UCLA Loneliness Scale - version 3 is 20 items measure that designed to measure one's subjective feelings of loneliness as well feelings of social isolation. Higher scores indicate more loneliness of individuals. The UCLA Loneliness Scale - version 3 is a psychometrically sound measure. The Cronbach's Alpha reliabilities of the measure were ranged from .89 to .94 across samples. The item-total correlations across samples were ranged from .28 to .75 . This measure had a high correlation with NYU Loneliness scale (Rubenstein \& Shaver, 1982) and Differential Loneliness scale (Schmidth \& Sermat, 1983) as reported by the author. All items are answered using a 4 -point Likert type scale $(1=$ never to $4=$ always $)$. The Bangla version of this scale comprised of 16 items. Among these, 7 were reversely scored. Total score ranged from 16 to 64. The Cronbach's Alpha, split-half reliability through Spearman-Brown coefficient, and test-retest reliability were .90 [.87, .91], .91, .83 [.71, .91] respectively. In the present study, the Cronbach's Alpha of this measure was .90 [.88, .92].

The General Health Questionnaire (GHQ-12): The GHQ-12 is 12 items scale that measures the mental health. Each item of the GHQ-12 was answered on a 4-point Likert type scale ranged from 1 (not at all) to 4 (much more than usual). The total score ranged from 12 to 48. Higher score on this scale indicated lower mental health. The Cronbach's Alpha of the Bangla GHQ-12 was .82 and the test-retest reliability was .57. In the present study, the Cronbach's Alpha of this scale was $.85[.82, .88]$.

\subsection{Procedure}

The questionnaire, comprised of above-mentioned scales and questions, was administered along with a personal information form and instructions sheet. The purposes and importance of this study explained to the respondents in the instructions sheet. They were assured about the usage and confidentiality of their responses. Respondents requested to read every item of the questionnaire carefully and also instructed to express their opinion as per the instructions were given to them. They were also instructed not to skip any item in the questionnaire. They were thanked for their cooperation in the study.

\section{Results}

\subsection{Data Characteristics}

Before proceeding toward final analysis, normality and homoskedasticity of the data were tested. The normality of the data tested through the residuals in regression analysis. Among normality statistics of residuals, skewness (-.26, SE $=.18)$ and kurtosis $(-.19, S E=.36)$ scores suggested that data were nearly normal. The Shapiro-Wilks test $(w=.99, p>.16)$ and Histogram and Normal Q-Q plot also suggested normality of the data. The homoskedasticity of the data was tested through the Breusch-Pagan and Koenkar test. The values of Breusch-Pagan $(1.43, p>.70)$ and Koenkar $(1.60, p>.66)$ test suggested homoskedasticity of the collected data. These characteristics of the data suggested that parametric tests would be applied to analyze the data. 


\subsection{Final Analysis}

The collected data were analyzed by descriptive statistics in order to estimate the mean and standard deviation of loneliness score, chatting on Facebook, Facebook timeline browsing, and mental health score. The obtained results of the analysis are presented in the Table 2.

Table 2. Descriptive statistics of loneliness, chatting on Facebook, Facebook timeline browsing, and mental health

\begin{tabular}{lcccc}
\hline Variable & Mean & Standard Deviation & \multicolumn{2}{c}{ 95\% Confidence Interval for Mean } \\
\cline { 3 - 5 } & & & Lower Bound & Upper Bound \\
\hline Loneliness & 35.56 & 9.58 & 34.15 & 36.97 \\
Chatting on Facebook & 1.85 hours & 1.28 hours & 1.66 hours & 2.03 hours \\
FB Timeline Browse & 1.85 hours & 1.50 hours & 1.63 hours & 2.07 hours \\
Mental Health & 34.96 & 6.74 & 33.97 & 35.95 \\
\hline
\end{tabular}

The collected data were subjected to the 'independent sample t-test' to assess the mean differences in loneliness score, chatting on Facebook, Facebook timeline browsing, and mental health score by respondents' gender and residence type. Results are presented in Table 3 and 4.

Table 3. Mean differences in loneliness, chatting on Facebook, Facebook timeline browsing, and mental health by gender

\begin{tabular}{|c|c|c|c|c|c|c|c|c|}
\hline \multirow[t]{2}{*}{ Variable } & \multicolumn{2}{|c|}{ Male } & \multicolumn{2}{|c|}{ Female } & \multirow[t]{2}{*}{$t(d f=178)$} & \multicolumn{2}{|c|}{$95 \%$ confidence interval } & \multirow[t]{2}{*}{$d$} \\
\hline & $M$ & $S D$ & $M$ & $S D$ & & Lower & Upper & \\
\hline Lon & 37.29 & 9.58 & 34.41 & 9.46 & $1.99 *$ & .30 & 5.74 & .30 \\
\hline CFB & 1.60 & 1.29 & 2.01 & 1.25 & $-2.09 *$ & -.79 & -.02 & -.32 \\
\hline FBTB & 1.50 & 1.30 & 2.08 & 1.59 & $-2.56^{*}$ & -1.02 & -.13 & -.39 \\
\hline MH & 35.86 & 6.33 & 34.36 & 6.96 & 1.47 & -.52 & 3.52 & .22 \\
\hline
\end{tabular}

$* p<.05$, Lon $=$ Loneliness, $\mathrm{CFB}=$ Chatting on Facebook, FBTB $=$ Facebook timeline browsing, $\mathrm{MH}=$ mental health, $d=$ effect size, male $=72$, female $=108$

Table 3 shows significant gender differences in loneliness ( $t$-value $=1.99, p<.048,95 \% C I[.30,5.74], d=.30)$, chatting on Facebook ( $t$-value $=-2.09, p<.04,95 \% C I[-.78,-.02], d=-.32)$, and Facebook timeline browsing $(t$-value $=-2.56$, $p<.01,95 \% C I[-1.02,-.13], d=-.39)$.

Table 4. Mean differences in loneliness, chatting on Facebook, Facebook timeline browsing, and mental health by respondents

\begin{tabular}{|c|c|c|c|c|c|c|c|c|}
\hline \multirow[t]{2}{*}{ Variable } & \multicolumn{2}{|c|}{ Suburban } & \multicolumn{2}{|c|}{ Urban } & \multirow[t]{2}{*}{$t(d f=178)$} & \multicolumn{2}{|c|}{$95 \%$ confidence interval } & \multirow[t]{2}{*}{$d$} \\
\hline & $M$ & $S D$ & $M$ & $S D$ & & Lower & Upper & \\
\hline Lon & 33.88 & 7.71 & 36.17 & 10.14 & -1.43 & -5.48 & .88 & -.24 \\
\hline CFB & 1.82 & 1.24 & 1.85 & 1.30 & -.15 & -.46 & .40 & -.02 \\
\hline FBTB & 1.74 & 1.15 & 1.89 & 1.61 & -.59 & -.65 & -.35 & -.09 \\
\hline MH & 36.23 & 5.72 & 34.50 & 7.03 & 1.53 & -.50 & 3.96 & .28 \\
\hline
\end{tabular}

Lon $=$ Loneliness, $\mathrm{CFB}=$ Chatting on Facebook, FBTB $=$ Facebook timeline browsing, $\mathrm{MH}=$ mental health, $d=$ effect size, suburban $=48$, urban $=132$

Table 4 shows non-significant mean differences in variables by respondents' residence type.

The collected data were subjected to the 'Pearson product moment correlation coefficient' to estimate the correlations among loneliness, chatting on Facebook, Facebook timeline browsing, and mental health. Results are presented in Table 5 . 
Table 5. Correlation matrix of the loneliness, chatting on Facebook, Facebook timeline browsing, and mental health

\begin{tabular}{llll}
\hline Variables & Loneliness & Chatting on Facebook & $\begin{array}{c}\text { Facebook Timeline } \\
\text { Browsing }\end{array}$ \\
\hline Chatting on Facebook & $-.05[-.19, .10]$ & & $.63^{* *}[.53, .71]$ \\
Facebook Timeline Browsing & $.18^{*}[.04, .32]$ & $-.13[-.27, .02]$ & $-.30 * *[-.42,-.16]$ \\
Mental Health & $-.68^{* *}[-.75,-.60]$ &
\end{tabular}

$* p<.05, * * p<.01$, values in the parentheses are $95 \%$ confidence interval

Table 5 shows that loneliness significantly correlated with Facebook timeline browsing $(r=.18, p<.02,95 \% \quad C I$ $[.04, .32])$, and mental health ( $r=-.68, p<.001,95 \% C I[-.75,-.60])$. Facebook timeline browsing significantly correlated with chatting on Facebook $(r=.63, p<.001,95 \% C I[.53, .71])$, and mental health $(r=-.30, p<.001,95 \% C I[-.42,-.16])$. Table also shows non-significant correlations of chatting on Facebook with loneliness and mental health. Because of non-significant correlations of chatting on Facebook with loneliness and mental health, our the hypothesized model was rejected and a new model hypothesized again. In the new hypothesized model, the only mediator variable was Facebook timeline browsing. As the Table 3 suggested significant gender differences in loneliness and Facebook timeline browsing, the moderation effect of gender also tested. The moderated mediation model was tested through the 'conditional process analysis' (Hayes, 2013). Among models, the model 7 fitted for the collected data of the present study. Results of the analysis are presented in Table 6 and Figure 2.

Table 6. Coefficients of Conditional Process Analysis

\begin{tabular}{|c|c|c|c|c|c|c|c|c|}
\hline \multirow[t]{3}{*}{ Antecedent } & \multicolumn{8}{|c|}{ Consequent } \\
\hline & \multicolumn{4}{|c|}{ FBTB (M) } & \multicolumn{4}{|c|}{ Mental Health (Y) } \\
\hline & $\boldsymbol{B}$ & $S E$ & $L L C I$ & ULCI & $B$ & $S E$ & $L L C I$ & ULCI \\
\hline Loneliness (X) & $.06 * *$ & .01 & .03 & .09 & $-.49 * *$ & .04 & -.53 & -.38 \\
\hline$F B T B(\mathrm{M})$ & & & & & $-.80 * *$ & .24 & -1.28 & -.32 \\
\hline Gender (W) & $1.91 *$ & .85 & .24 & 3.59 & & & & \\
\hline $\mathrm{X}^{*} \mathrm{~W}$ & $-.07 * *$ & .02 & -.12 & -.03 & & & & \\
\hline \multirow[t]{2}{*}{ Constant } & -.07 & .52 & -1.09 & .95 & 52.72 & 1.40 & 49.97 & 55.47 \\
\hline & \multicolumn{4}{|c|}{$R^{2}=.13, F(3,176)=8.74, p<.001, f^{2}=.15$} & \multicolumn{4}{|c|}{$R^{2}=.50, F(2,177)=87.67, p<.001, f^{2}=1.0$} \\
\hline
\end{tabular}

Conditional indirect effect of loneliness on mental health: for male $(B=.01, S E=.01, p>.05,95 \% C I$ of $B$ [-.02, .04]), for female $(B=.05, S E=.02, p<.05,95 \% C I$ of $B[-.10,1.02])$.

$* p<.05, * * p<.01, \mathrm{X}=$ independent variable, $\mathrm{M}=$ mediator variable, $\mathrm{W}=$ moderator variable, $\mathrm{Y}=$ dependent variable, $B=$ unstandardized Beta, $S E=$ standard error, $L L C I=$ lower limit of $95 \%$ confidence interval, UCLI $=$ upper limit of 95\% confidence interval, $F B T B=$ Facebook Timeline Browsing, $f^{2}=$ effect size

Table 6 shows a relationship of moderated mediation among loneliness, Facebook timeline browsing, mental health, and gender. The loneliness, Facebook timeline browsing, and gender explained $50 \%$ variance of the mental health $\left(R^{2}=.50\right.$, $\left.f^{2}=1.0\right)$. This table also shows that loneliness had the positive impact on Facebook timeline browsing $(B=.06, S E=.01$, $p<.001,95 \% C I$ of $B[.03, .09])$. Gender played a moderating role in the relationship between these two variables. The mental health negatively influenced by Facebook timeline browsing $(B=-.80, S E=.24, p<.001,95 \% C I$ of $B[-1.28$, -.32]), and loneliness ( $B=-.49, S E=.04, p<.001,95 \% C I$ of $B$ [-.53, -.38]). 


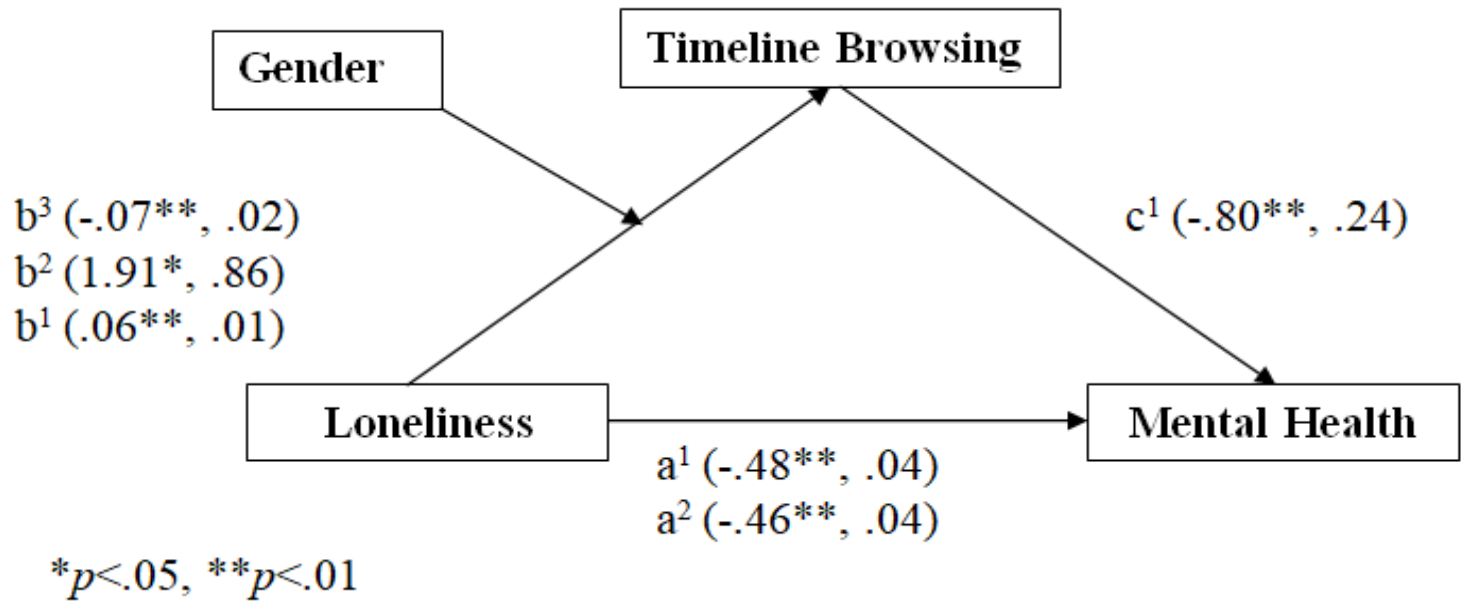

Figure 2. Relationship of a moderated mediation model among loneliness, Facebook timeline browsing, mental health, and gender

Here, a represents the direct effect of loneliness on mental health under different conditions, $b^{1}$ represents the effect of loneliness, $b^{2}$ represents the effect of gender, and $b^{3}$ represents the interaction effect of loneliness and gender on Facebook timeline browsing, and c represents the effect of Facebook timeline browsing on mental health.

\section{Discussion}

A new environment always poses some form of difficulties related to adjustment. Newly enrolled students, at the undergraduate programs, always face some form of such difficulties. Their age belongs to the transition from adolescent to adulthood. This stage of life always treated as emerging adulthood. In this stage, the feeling of loneliness creates some problem to the adjustment in a new environment. The present study was designed to explore the relationship between loneliness and mental health that mediated by chatting on Facebook, and Facebook timeline browsing behavior of first-year undergraduate students.

Information from the Table 3 suggested significant gender differences in feelings of loneliness, chatting on Facebook, Facebook timeline browsing. Male students had more subjective feelings of loneliness than female students. Fujimori, Hayashi, Fujiwara, and Matsusaka (2017) found significant gender differences among university students. Upmanyu, Upmanyu, and Dhingra (1992) conducted a study on a sample of 200 students (aged 16-18 years old) to find out gender differences in loneliness and coping strategies to deal with loneliness. They found that male were more lonely than female. Table 3 also showed that females were significantly spent more time on chatting with virtual friends through Facebook than males. Females also spent more time on timeline browsing than males. Biernatowska, Balcerowska, \& Bereznowski (2017) found that females were higher in subjective time spending on Facebook than male. Mazman and Usluel (2011) reported that women were using Facebook for maintaining an existing relationship than men. In their study, Thompson and Lougheed (2012) found that women reported more time spending on Facebook than men, lose sleep for Facebook, felt anxious when failed to get access on Facebook.

Table 5 showed that loneliness had significant but weak positive correlation with Facebook timeline browsing. This table also showed that loneliness had a significantly negative correlation with mental health. Mental health also significantly correlated with Facebook timeline browsing but, non-significant correlation with chatting on Facebook. However, our hypothesized model about the mediating role of chatting on Facebook, and Facebook timeline browsing was not supported by the results from Table 5. Depending on the results from Table 3 and 5 , the model was revised, and a moderated mediation model was formed and tested. Results from Table 6 suggested that loneliness had a positive effect on Facebook timeline browsing. Individuals had more subjective feelings of loneliness, spent more time in browsing Facebook timeline. Both loneliness and Facebook timeline browsing were negative predictors of mental health. More subjective feelings of loneliness and spending more time on browsing timeline lead to worse mental health. Moreover, the conditional indirect effect of loneliness (for female) on mental health was significant. Studies suggested that the feeling of loneliness was negatively related to the intense use of Facebook (Shetter et al., 2017). One reason for using more Facebook might be seeking emotional support from the virtual world. Studies also suggested that loneliness linked to anxiety, depression, suicidal ideation, hopelessness, etc. (Cacioppo et al., 2006; Johnson et al., 2001; Pervin \& Ferdowshi, 2016; Richardson et al., 2017; Roberts et al., 1998). Figure 1 suggested a mediating role of Facebook timeline browsing in the relationship between loneliness and mental health. Individuals might be connected on Facebook more to reduce 
loneliness. The excessive use of SNSs (i.e., Facebook, Twitter, etc.) leads to addiction on the sites. It has a negative impact on daily activities, interpersonal relations, and psychological well-being. A study suggested that maintaining poor social relationship leads to worse mental health (Santini et al., 2015). Individuals, having the Facebook addiction, were at a high risk of developing somatic symptoms, social dysfunction, anxiety, insomnia, depression, and abnormal general mental health (Hanprathet, Manwong, Khumsri, Yingyeun, \& Phanasathit, 2015). One possible reason for the negative relationship between Facebook timeline browsing and mental health is that more engagement on Facebook timeline might lead to the social comparison on Facebook. The negative comparisons with others and envy lead to stress and poor mental health. The study suggested that Facebook users, who use this SNS frequently, believed that other Facebook users, who were unknown to them, were more successful and happier than themselves (Chou \& Edge, 2012). They might compare their offline selves to the ideal online selves which has a detrimental effect on the well-being of the users. Vogel, Rose, Roberts, and Eckles (2014) found that social comparison negatively related to Facebook use and self-esteem.

Limitations and Recommendations: People may have the different level of loneliness at different age levels due to various causes. In the present study, the loneliness that related to the adjustment in the new environment at the university was considered. The non-probability sampling techniques were used to select the sample in this study. A study including a large sample would be taken to reduce the systematic error. In this study, why Facebook timeline browsing negatively influenced the mental health is not identified. Why lonely people more browsed Facebook timeline? The answer to this question is not addressed in this study that was quantitative in nature. A study extensive study using mixed design (quantitative and qualitative) would be conducted to find out reasons of above questions arose in this study. This future study might also address following questions - are they actively browse Facebook timeline or not? What their behavior pattern on Facebook while browsing Facebook timeline? Why they actively or passively browse the Facebook timeline? Answer of these open-ended questions would be helpful to explain the relationship between loneliness and mental health that mediated by Facebook timeline browsing.

\section{Acknowledgement}

I sincerely thank Mohammad Alamgir Hossain, Assistant Professor, Department of Psychology, University of Chittagong, for her cordial help during data collection of the study.

\section{References}

Ahmed, O., \& Hossain, M. A. (2018). The Bangla UCLA Loneliness Scale (Version 3). Unpublished Manuscript. Department of Psychology, University of Chittagong, Chittagong.

Ahmed, O., Uddin, M. K., \& Khanam, M. (2016). Motivation and Learning Strategies as Strong Predictors of Academic Achievement. Indian Journal of Psychology and Education, 6(1), 120-132.

Biernatowska, A., Balcerowska, J. M., \& Bereznowski, P. (2017).Gender differences in using Facebook-preliminary analysis. In J. Nyćkowiak\& J. Leśny (Eds.), Badania i Rozwój Młodych Naukowców w Polsce - Społeczeństwo: psychologia i socjologia (pp. 13-18). Poznań, Poland: Młodzi Naukowcy.

Bozoglan, B., Demirer, V., \& Sahin, I. (2013). Loneliness, Self-esteem, and Life Satisfaction as Predictors of Internet Addiction: A Cross-sectional Study among Turkish University Students. Scandinavian Journal of Psychology, 54(4), 313-319. https://doi.org/10.1111/sjop.12049

Brage, D., Meredith, W., \& Woodward, J. (1993).Correlates of Loneliness among Midwestern Adolescents. Adolescence, 28(111), 685-694. (Abstract)

Cacioppo, J. T., Hawkley, L. C., Ernst, J. M., Burleson, M., Berntson, G. G., Nouriani, B., \& Spiegel, D. (2006). Loneliness with a Nomological Net: An Evolutionary Perspective. Journal of Research in Personality, 40, 1054-1085. https://doi.org/10.1016/j.jrp.2005.11.007

Chou, H. T. G., \& Edge, N. (2012). "They are happier and having better lives than I am": The Impact of Using Facebook on Perceptions of Others' Lives. Cyberpsychology, Behavior, and Social Networking, 15, 117-121. https://doi.org/10.1089/cyber.2011.0324

Civitci, N., \& Civitci, A. (2009). Self-esteem as Mediator and Moderator of the Relationship between Loneliness and Life Satisfaction in Adolescents. Personality and Individual Differences, 47, 954-958. https://doi.org/10.1016/j.paid.2009.07.022

Fujimori, A., Hayashi, H., Fujiwara, Y., \& Matsusaka, T. (2017). Influences of Attachment Style, Family Functions and Gender Differences on Loneliness in Japanese University Students. Psychology, 8, 654-662.

https://doi.org/10.4236/psych.2017.84042

Gierveld, J. D., \& Tilburg T. V. (2006). A 6-item Scale for Overall, Emotional, and Social Loneliness - Confirmatory 
Tests on Survey Data. Research on Aging, 28(5), 582-598. https://doi.org/10.1177/0164027506289723

Ginsber, D., \& Burke, M. (2017, December 15). Hard Questions: Is Spending Time on Social Media Bad for Us? Retrieved from https://newsroom.fb.com/news/2017/12/hard-questions-is-spending-time-on-social-media-bad-for-us/

Goldberg, D. (1978). Manual of the General Health Questionnaire. Windsor: NFER-Nelson.

Hanprathet, M., Manwong, M., Khumsri, J., Yingyeun, R., \& Phanasathit, M. (2015). Facebook Addiction and Its Relationship with Mental Health among Thai High School Students. Journal of the Medical Association of Thailand, 98(Suppl. 3), 81-91.

Hayes, A. F. (2013). Introduction to Mediation, Moderation, and Conditional Process Analysis: A Regression-based Approach. New York, NY, US: Guilford Press.

Ilyas, Q. S. M., \& Aeysha, M. (2001). Bangali version of the Goldberg General Health Questionnaire (GHQ).Unpublished Manuscript. Department of Psychology, University of Dhaka, Dhaka.

Johnson, H. D., LaVoie, J. C., Spenceri, M. C., \& Mahoney-Wernli, M. A. (2001). Peer Conflict Avoidance: Associations with Loneliness, Social Anxiety, and Social Avoidance. Psychological Reports, 88(1), 227-235. https://doi.org/10.2466/pr0.2001.88.1.227

Lau, S., Chan, D. W. K., \& Lau, P. S. Y. (1999). Facets of Loneliness and Depression among Chinese Children and Adolescents. Journal of Social Psychology, 139(6), 713-730. https://doi.org/10.1080/00224549909598251

Mazman, S. G., \& Usluel, Y. K. (2011). Gender Differences in Using Social Networks. The Turkish Online Journal of Educational Technology, 10, 133-139. Retrieved from http://www.tojet.net/

Meltzer, H., Bebbington, P., Dennis, M. S., Jenkins, R., McManus, S., \& Brugha, T. S. (2013). Feelings of Loneliness among Adults with Mental Disorder. Social Psychiatry and Psychiatric Epidemiology, 28(1), 5-13. http://dx.doi.org/10.1007/s00127-014-0977-y

Ministry of Education, (2012). National Education Policy (2010). Retrieved from http://www.moedu.gov.bd/

Morahan-Martin, J., \& Schumacher, P. (2003). Loneliness and Social Uses of the Internet. Computers in Human Behavior, 19(6), 659-671. https://doi.org/10.1016/S0747-5632(03)00040-2

Peplau, L. A., \& Perlman, D. (1982). Loneliness: A Sourcebook of Current Theory, Research, and Therapy. New York, NY: Wiley.

Pervin, M. M., \& Ferdowshi, N. (2016). Suicidal Ideation in Relation to Depression, Loneliness, and Hopelessness among University Students. Dhaka University Journal of Biological Sciences, 25(1), 57-64. https://doi.org/10.3329/dujbs.v25i1.28495

Richardson, T., Elliott, P., \& Roberts, R. (2017). Relationship between Loneliness and Mental Health in Students. Journal of Public Mental Health, 16(2), 48-54. https://doi.org/10.1108/JPMH-03-2016-0013

Robbins, S. B., Lauver, K., Le, H., Davis, D., Langley, R., \& Carlstrom, A. (2004). Do Psychosocial and Study Skill Factors Predict College Outcomes? A Meta-analysis. Psychological Bulletin, 130, 261-288. http://dx.doi.org/10.1037/0033-2909.130.2.261

Roberts, R. E., Roberts, C. R., \& Chen, R. Y. (1998). Suicidal Thinking among Adolescents with a History of Attempted Suicide. Journal of the American Academy of Child and Adolescent Psychiatry, 37(12), 1294-1300. https://doi.org/10.1097/00004583-199812000-00013

Rokach, A., \& Brock, H. (1997). Loneliness and the Effects of Life Changes. The Journal of Psychology: Interdisciplinary and Applied, 131(3), 284-298. https://doi.org/10.1080/00223989709603515

Rokach, A., \& Neto, F. (2000). Causes of Loneliness in Adolescence: A Cross-cultural Study. International Journal of Adolescence and Youth, 8, 65-80. https://doi.org/10.1080/02673843.2000.9747842

Rosen, L. D., Whaling, K., Rab, S., Carrier, L. M., \& Cheever, N. A. (2013). Is Facebook Creating "iDisorders"? The Link between Clinical Symptoms of Psychiatric Disorders and Technology Use, Attitudes, and Anxiety. Computers in Human Behavior, 29(3), 1243-1254. https://doi.org/10.1016/j.chb.2012.11.012

Rubenstein, C. M., \& Shaver, P. (1982). The Experience of Loneliness. In L. A. Peplau \& D. Perlman (Eds.), Loneliness: A Sourcebook of Current Theory, Research and Therapy (pp. 206-123). New York, NY: John Wiley \& Sons.

Russell, D. (1996). UCLA Loneliness Scale (Version 3): Reliability, Validity, and Factor Structure. Journal of Personality Assessment, 66, 20-40. https://doi.org/10.1207/s15327752jpa6601_2 
Russell, D., Peplau, L. A., \& Cutrona, C. E. (1980). The Revised UCLA Loneliness Scale: Concurrent and Discriminant Validity Evidence. Journal of Personality and Social Psychology, 39, 472-480. http://dx.doi.org/10.1037/0022-3514.39.3.472

Santini, Z. I., Koyanagi, A., Tyrovolas, S., Mason, C., \& Haro, J. M. (2015). The Association between Social Relationships and Depression: a Systematic Review. Journal of Affective Disorders, 175, 53-65. https://doi.org/10.1016/j.jad.2014.12.049

Schmidt, N., \& Sermat, V. (1983). Measuring Loneliness in Different Relationships. Journal of Personality and Social Psychology, 44, 1038-1047. https://doi.org/10.1037/0022-3514.44.5.1038

Sheldon, P. (2008). The Relationship Between Unwillingness-to-Communicate and Students' Facebook Use. Journal of Media Psychology, 20(2), 67-75. https://doi.org/10.1027/1864-1105.20.2.67

Shettar, M., Karkal, R., Kakunje, A., Mendonsa, R. D., \& Chandran, V. V. M. (2017). Facebook Addiction and Loneliness in the Post-graduate Students of a University in Southern India. International Journal of Social Psychiatry, 63(4), 325-329. https://doi.org/10.1177\%2F0020764017705895

State Counter (2018). Social Media Stats in Bangladesh-February, 2018. Retrieved from http://gs.statcounter.com/social-media-stats/all/bangladesh/\#monthly-201712-201802

Stensland, S. O., Thoresen, S., Wentzel-Larsen, T., Zwart, J.A., \& Dyb, G. (2014). Recurrent headache and interpersonal violence in adolescence: The Roles of Psychological Distress, Loneliness and Family Cohesion: The HUNT Study. Journal of Headache and Pain, 15(1), 1-9. https://doi.org/10.1186/1129-2377-15-35

Sultana, T. (2018). Personality Traits, Social Networking Sites Use and Addiction, and Mental Health among University Students. Unpublished Masters' thesis.University of Chittagong, Chittagong, Bangladesh.

Thompson, S. H., \& Lougheed, E. (2012). Frazzled by Facebook? An Exploratory Study of Gender Differences in Social Network Communication among Undergraduate Men and Women. College Student Journal, 46(1), 88-99. Retrieved from https://www.learntechlib.org/p/91217/

Upmanyu, V. V., Upmanyu, S., \& Dhingra, M. (1992). Gender Differences in Loneliness. Journal of Personality and Clinical Studies, 8(1-2), 161-166. (Abstract)

Vanhalst, J., Luyckx, K., \& Goossens, L. (2014). Experiencing Loneliness in Adolescence: A Matter of Individual Characteristics, Negative Peer Experiences, or Both? Social Development, 23(1), 100-118. https://doi.org/10.1111/sode.12019

Vogel, E. A., Rose, J. P., Roberts, L. R., \& Eckles, K. (2014). Social Comparison, Social Media, and Self-Esteem. Psychology of Popular Media Culture, 3(4), 206-222. https://doi.org/10.1037/ppm0000047

Weiss, R. S. (1973). Loneliness: The Experience of Emotional and Social Isolation. Cambridge, MA: The MIT press.

Wintre, M. G., \& Bowers, C. D. (2007). Predictors of Persistence to Graduation: Extending a Model and Data on the Transition to University Model. Canadian Journal of Behavioural Science, 39, 220-234. https://doi.org/10.1037/cjbs2007017

Woodhouse, S. S., Dykas, M. J., \& Cassidy, J. (2012). Loneliness and Peer Relations in Adolescence. Social Development, 21(2), 273-293. https://doi.org/10.1111/j.1467-9507.2011.00611.x

World Health Organization. (2004). Promoting Mental Health: Concepts, Emerging Evidence, Practice: Summary Report. Geneva: World Health Organization.

\section{Copyrights}

Copyright for this article is retained by the author(s), with first publication rights granted to the journal.

This is an open-access article distributed under the terms and conditions of the Creative Commons Attribution license which permits unrestricted use, distribution, and reproduction in any medium, provided the original work is properly cited. 